\title{
Mini Nutritional Assessment of rural elderly people in Bangladesh: the impact of demographic, socio-economic and health factors
}

\author{
Zarina Nahar Kabir ${ }^{1, *}$, Tamanna Ferdous ${ }^{1}$, Tommy Cederholm², \\ Masuma Akter Khanam ${ }^{1,3}$, Kim Streatfied ${ }^{3}$ and Åke Wahlin ${ }^{1,4}$ \\ 'Division of Geriatric Epidemiology, Neurotec, Karolinska Institutet, Box 6401, SE-1 1382 Stockholm, Sweden: \\ ${ }^{2}$ Clinical Nutrition and Metabolism, Institute of Public Health, Uppsala University, Uppsala, Sweden: ${ }^{3}$ ICDDR, B: \\ Centre for Health and Population Research, Dhaka, Bangladesh: ${ }^{4}$ Department of Psychology, Stockholm University, \\ Stockholm, Sweden
}

Submitted 11 October 2005: Accepted 14 February 2006

\begin{abstract}
Objective: In stating the Millennium Development Goals, the United Nations aims to halve malnutrition around the world by 2015. Nutritional status of the elderly population in low-income countries is seldom focused upon. The present study aimed to evaluate the magnitude of malnutrition among an elderly population in rural Bangladesh.

Design and setting: Data collection for a multidimensional cross-sectional study of community-based elderly people aged 60 years and over was conducted in a rural area in Bangladesh.

Subjects: Of 850 randomly selected elderly individuals, 625 participated in home interviews. Complete nutritional information was available for 457 individuals (mean age $69 \pm 8$ years, $55 \%$ female). Nutritional status was assessed using an adapted form of the Mini Nutritional Assessment (MNA) including body mass index (BMI). Age, sex, education, household expenditure on food and self-reported health problems were investigated as potential predictors of nutritional status.

Results: $\mathrm{BMI}<18.5 \mathrm{~kg} \mathrm{~m}^{-2}$, indicating chronic energy deficiency, was found in $50 \%$ of the population. MNA revealed a prevalence of $26 \%$ for protein-energy malnutrition and $62 \%$ for risk of malnutrition. Health problems rather than age had a negative impact on nutritional status. Level of education and food expenditure were directly associated with nutritional status.

Conclusion: In order to reduce world hunger by half in the coming decade, it is important to recognise that a substantial proportion of the elderly population, particularly in low-income countries, is undernourished.
\end{abstract}

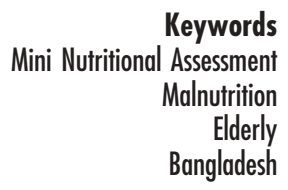

All 191 member states of the United Nations have pledged to meet the Millennium Development Goals by 2015, only a decade away ${ }^{1}$. The first of the eight stated goals is to eradicate extreme poverty and hunger. One of the indicators of this is to halve the number of people who are undernourished ${ }^{2}$. In order to achieve this goal, Svedberg $^{3}$ notes that five Ws will need to be addressed: what constitutes undernutrition; who the undernourished are; where they are located; when they are undernourished; and why they are undernourished. This study focuses on the 'who' and to some extent the 'why' questions.

Of the 852 million people estimated to be undernourished during 2000-2002 worldwide, 95\% lived in developing countries ${ }^{4}$. Nearly one-third of the Bangladeshi population, or more than 42 million people, is malnourished in terms of undernutrition, with a daily dietary energy supply of less than $2190 \mathrm{kcal}$ per capita ${ }^{4}$.

In Western societies, elderly persons are more likely than younger adults to suffer from malnutrition ${ }^{5}$. A variety of functional, psychological, economic and social factors result in poor diet, qualitatively and quantitatively, that negatively influences the nutritional status of older people ${ }^{6}$. Malnourishment in the older population is also reported to be a consequence of inadequate food intake, underlying illnesses, gender (with women being at higher risk) and economic vulnerability ${ }^{7-9}$.

Implications of undernutrition in the elderly are manifold. It can reduce functional status and worsen existing medical problems, and hence impact negatively on health-related quality of life. Omran and Morley ${ }^{10}$ cite studies reporting that undernutrition increases the risk of 
respiratory and cardiac problems, infections, deep venous thrombosis, pressure ulcer, perioperative mortality and multiple organ failure. Several other studies identify malnutrition as a determinant of increased risk of frailty, morbidity and even mortality ${ }^{11-13}$.

The elderly population (aged 60 years and over) is rapidly increasing worldwide and the increase will, both in relative and absolute terms, be much more dramatic in low-income than in high-income regions of the world ${ }^{14}$. Out of a population of almost 144 million in Bangladesh, more than 7 million (5.1\%) are aged 60 years and above ${ }^{15}$. By 2020, Bangladesh will, with a projected 14 million elderly people, be one of the 10 nations with the largest elderly population ${ }^{16}$.

Information on the nutritional status of older persons in low-income countries such as Bangladesh is scarce and not well documented ${ }^{17}$. Research and public health activities in Bangladesh have so far focused largely on nutritional aspects related to children and women of reproductive age ${ }^{18,19}$.

The present paper aims to inform about the magnitude of malnutrition that prevails among an elderly population in rural Bangladesh. Demographic, socio-economic and health determinants of malnutrition are also investigated.

\section{Methods}

\section{Participants}

During August 2003 to January 2004, data collection for a multidimensional cross-sectional study of elderly people aged 60 years and over was conducted in Matlab, a rural area $55 \mathrm{~km}$ south-east of Dhaka city. ICDDR,B has been maintaining a Demographic Surveillance System in the area since 1966 that currently covers a population of approximately 220000 across 142 villages. A total number of 850 community-dwelling elderly individuals aged 60 years and over was randomly selected from the surveillance database maintained by ICDDR,B. On obtaining informed consent, participants were first interviewed by trained interviewers at their homes. They were then invited to clinical examinations conducted by physicians at a nearby health centre. From the selected target population of 850,63 were dead before the beginning of the study, 38 refused to participate, 11 had migrated, 93 could not be reached, 18 were found to be registered twice in the surveillance database and two persons were found to be under age (after cross-checking age). A total of 625 individuals participated in the home interview, of whom 473 underwent clinical examination. Results presented here include only those elderly individuals for whom complete data on nutritional status are available $(n=457)$. Informed consent was obtained from participants prior to interview. The study was approved by ethics committees at ICDDR,B in Dhaka and the Karolinska Institutet in Stockholm.

\section{Background information}

Demographic, socio-economic information and data on self-reported morbidity were collected during the home interview. The demographic indicators used here include age and sex of the respondent. Socio-economic status (SES) of the respondent is indicated by years of schooling and information about per capita daily expenditure on food items in the respondent's household. This was calculated by using the number of household members as denominator. Health status of the elderly respondents in this study is indicated by self-reported health problems. These were categorised into respiratory (uncomfortable feeling in the chest, cough, asthma, problem with breathing), stomach and sensory (vision and hearing), and problem with pain (waist, joint) and sleep.

\section{Assessment of nutritional status}

Nutritional status was assessed by physicians using the Mini Nutritional Assessment (MNA), which is an instrument specifically designed for elderly people $\mathrm{e}^{20}$. It is a simple and rapid tool with high sensitivity (96\%) and specificity (98\%) to screen older persons for malnutrition $^{21}$. The MNA, comprising 18 items, is based on the following components: anthropometric measurements, dietary questionnaire, global health and social assessment, and subjective assessment of health and nutrition. The instrument was used in this study in its entirety but with a few modifications. Although the instrument is not specifically stated as one to be used only in Western elderly populations, it states certain cut-offs such as for body mass index (BMI) that are used for Western populations. The World Health Organization (WHO) recommends a lower cut-off $\left(<18.5 \mathrm{~kg} \mathrm{~m}^{-2}\right)$ to classify adults as underweight than that suggested in the MNA. Therefore, in this study we used the BMI cut-off suggested by WHO, as done in other similar studies ${ }^{22,23}$. Also, due to a lack of information on calf circumference and the inappropriateness of a query regarding living in a nursing home (nursing homes for sick elderly persons do not exist in rural Bangladesh), these two items were dropped from the current assessment. Accordingly, the total assessment scores were adjusted by lowering 2 points from that suggested by the original MNA. The original MNA instrument classifies elderly persons into three stages of nutritional status based on scores ranging from 0 to 30 . The adjusted instrument used in the present study also categorised individuals into three levels of nutritional status but based on scores ranging from 0 to 28 and a lowering of cut-offs by 2 points: accordingly, a score of $\geq 22$ indicates satisfactory nutritional status, a score of 15 to 21.5 indicates risk of malnutrition and a score $<15$ indicates protein-energy malnutrition (PEM).

Three specific items of MNA related to consumption were analysed separately in order to investigate possible associations between consumption and socio-economic status. These items are daily consumption of full meals 
(number of full meals), protein (meat, fish, beans, eggs and dairy products), and fruits and vegetables.

\section{Statistical analyses}

Independent variables used in this study include age, sex, socio-economic status (indicated by years of education and per capita daily household expenditure on food) and self-reported health problems. The main outcome studied is nutritional status as indexed by MNA. Descriptive analyses were performed to report prevalence, and the independent $t$-test used to compare means between groups. Finally, hierarchical stepwise linear regression was done in order to identify predictors of nutritional status and to examine variations in nutritional status accounted for by the predictors. In these analyses, a block of demographic indicators (age in years, sex) was entered in the first step. In the second step, the block of socioeconomic indicators (i.e. years of schooling, per capita daily household expenditure in Taka) was entered. Finally, in the third step, the block of health indicators (respiratory problem, stomach problem, pain, sensory problem, sleeping problem) was entered. Thus, the additional impact of each block of indicators on MNA scores was examined after removal of variance accounted for by the previous block of indicators.

\section{Results}

Median age was 68 years and equal between men and women (see Table 1). Almost 60\% of the study sample was illiterate, and the proportion of literacy among women was significantly lower than that among men. The mean per capita household expenditure on food was similar between men and women. Finally, in self-reported health problems, for all the stated problems a higher proportion of women reported complaints than men (see Table 2).
Comparisons between respondents and drop-outs on background and health profile indicated that the drop-outs were mostly women, older and had lower socio-economic status as assessed by the indicators (Tables 1 and 2). The drop-out group consisted mainly of those who did not participate in the clinical investigation $(n=152)$ and those for whom nutritional data were missing $(n=16)$ although they participated in the clinical examination.

\section{Prevalence of malnutrition}

According to the WHO categorisation of nutritional status based on BMI, i.e. $<18.5 \mathrm{~kg} \mathrm{~m}^{-2}, 49.7 \%$ of the elderly people in this study suffered from chronic energy deficiency (CED). No significant difference was found between men $\left(19.1 \pm 2.7 \mathrm{~kg} \mathrm{~m}^{-2}\right)$ and women $\left(18.9 \pm 3.4 \mathrm{~kg} \mathrm{~m}^{-2}\right)$ on the basis of mean BMI. In contrast, women in this study had a significantly lower mean MNA score (17.2) than men (18.1) $(P=0.003)$. According to MNA categorisation, the prevalence of PEM and risk of malnutrition in this sample was $26 \%$ and $62 \%$, respectively (Fig. 1). The corresponding figures for elderly men and women were $22 \%$ and $63 \%$, and $29 \%$ and $61 \%$, respectively.

\section{Consumption pattern by nutritional status}

Figure 2 indicates level of consumption by nutritional status. The highest proportion of the well-nourished group took three full meals per day and a third of the undernourished group survived on one meal a day $(P<0.001)$. However, it is notable that substantial proportions of those categorised as undernourished or at risk of malnourishment consumed two or three full meals a day, indicating that the content of the meals may be nutritionally poor (Fig. 2a). Protein consumption was low across all groups of nutritional categories, and lowest in the undernourished group $(P<0.01)$ (Fig. 2b). Absence of daily consumption of fruits and vegetables was also

Table 1 Demographic and socio-economic profile of respondents and drop-outs

\begin{tabular}{|c|c|c|c|c|}
\hline & $\begin{array}{c}\text { Men } \\
(n=208)\end{array}$ & $\begin{array}{l}\text { Women } \\
(n=249)\end{array}$ & $\begin{array}{c}\text { Total } \\
(n=457)\end{array}$ & $\begin{array}{c}\text { Drop-out and missing } \\
\text { data on MNA }(n=168)\end{array}$ \\
\hline \multicolumn{5}{|l|}{ Demographic information } \\
\hline $\operatorname{Sex}(\%)$ & 45.5 & 54.5 & & Women: 72 \\
\hline \multicolumn{5}{|l|}{ Age distribution (\%) } \\
\hline $60-64$ years & 28 & 35 & 32 & 23 \\
\hline $65-69$ years & 25 & 23 & 24 & 24 \\
\hline $70-74$ years & 20 & 18 & 18 & 23 \\
\hline $75-79$ years & 11 & 13 & 12 & 16 \\
\hline$\geq 80$ years & 16 & 11 & 13 & 14 \\
\hline Age (years), median (IQR) & $68(63-75)$ & $68(63-74)$ & $68(63-75)$ & $70(65-77)$ \\
\hline \multicolumn{5}{|l|}{ Socio-economic information } \\
\hline Literate (\%) & 59 & 21 & $39+$ & 28 \\
\hline Years of schooling, mean (SD) & $3.1(3.5)$ & $0.8(1.6)$ & $1.9(3.0) \dagger$ & $1.2(2.3)$ \\
\hline $\begin{array}{l}\text { Per capita daily household expenditure } \\
\text { on food (Taka*), mean (SD) }\end{array}$ & $20.38(13.38)$ & $21.02(20.19)$ & $20.7(17.4) \ddagger$ & $17.9(11.0)$ \\
\hline
\end{tabular}

MNA - Mini Nutritional Assessment; IQR - interquartile range; SD - standard deviation.

* Taka 57 = \$US 1 during the study period.

† Data missing for five individuals.

$\ddagger$ Data missing for four individuals (two men, two women). 
Table 2 Health profile of respondents and drop-outs: percentage reporting health problems

\begin{tabular}{lcccc}
\hline & Men $(n=208)$ & Women $(n=249)$ & Total $(n=457)$ & $\begin{array}{c}\text { Drop-out and missing } \\
\text { data on MNA }(n=168)\end{array}$ \\
\hline Respiratory problem & 63.8 & 72.7 & 68.6 & 58.3 \\
Stomach problem & 54.8 & 59.0 & 57.1 & 58.3 \\
Pain problem & 79.8 & 93.1 & 87.1 & 84.5 \\
Sensory problem & 82.7 & 91.6 & 87.5 & 91.7 \\
Sleeping problem & 50.0 & 59.4 & 55.1 & 51.2 \\
\hline
\end{tabular}

MNA - Mini Nutritional Assessment.

most pronounced in the undernourished group $(P<0.001)$ (Fig. 2c).

\section{Determinants of nutritional status}

Table 3 shows results of the hierarchical linear regression analyses. In these analyses, demographic information (i.e. age and sex) was entered in the first step, information regarding years of schooling and per capita daily household expenditure in the second step, and a block of health indicators was entered in the third step. These analyses indicated that demographic indicators accounted for approximately $3 \%$ of the variation in MNA scores and that older age $(-\beta)$ and being a woman $(-\beta)$ were associated with lower MNA scores (Table 3). Furthermore, the block of socio-economic variables accounted for an additional $4 \%$ of MNA variation. Among these variables, longer education $(\beta)$ and higher per capita daily household expenditure $(\beta)$ were significantly associated with higher MNA scores. Finally, the block of self-reported health indicators accounted for an additional 9\% of the variation at the mean level of the demographic and economic information. All health problems $(-\beta)$ except pain were significantly associated with lower MNA scores.

\section{Discussion}

Of the five Ws identified by Svedberg $^{3}$ in order to reduce prevalence of undernutrition, this paper mainly aids in

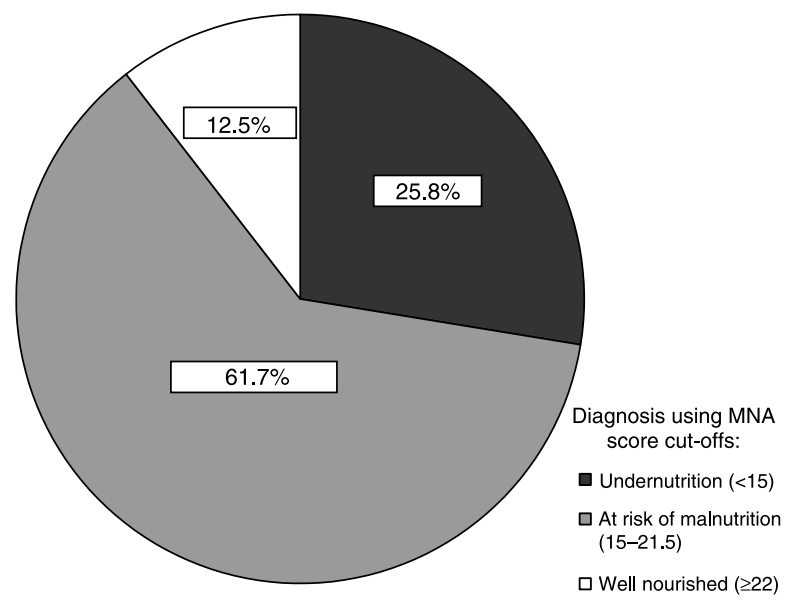

Fig. 1 Nutritional status of elderly persons in a rural area in Bangladesh as evaluated by Mini Nutritional Assessment (MNA) shedding light on the 'who' question and to some extent provides tentative answers to the 'why' question.

\section{Who are undernourished?}

Using anthropometric measures, a study from rural Malawi demonstrates that undernutrition among its older people is a significant problem ${ }^{24}$. In central Uganda, the prevalence of malnutrition, based on BMI and mid upper-arm circumference, within the population aged $60-90$ years is reported to be $33 \%$ and $52 \%$, respectively ${ }^{25}$. Accordingly, the present study shows that a substantial segment of elderly individuals in rural Bangladesh are either undernourished or at risk of malnourishment. According to MNA score, our results show a $26 \%$ prevalence of PEM and $62 \%$ to be at risk of malnutrition, totalling to a magnitude of nearly $90 \%$ of elderly people with a grim nutritional profile. It should be noted that, due to deletion of items such as calf circumference and the query regarding living in a nursing home from the instrument, the cut-offs were lowered by 2 points. The MNA instrument is not validated for use in elderly populations in low-income countries; thus the results need to be interpreted somewhat cautiously. Using the international criteria on classification of CED as BMI $<18.5 \mathrm{~kg} \mathrm{~m}^{-2}$, one of the rare studies on adult nutrition in Bangladesh reports CED prevalence of 63\% and $72 \%$ among adults (19 years and older) in two selected rural areas ${ }^{26}$. Other studies from Bangladesh also report high prevalences of nutrient deficiencies such as calcium, iron and vitamin $\mathrm{A}^{18,26-28}$. However, these figures are not comparable with the results of the current study as they included mostly younger populations and used other indicators for assessing nutritional status. Interestingly, another Asian study on Japanese elderly that employed both MNA and the same BMI cut-off ${ }^{22}$ reported very similar figures (i.e. 20\% malnourished and 58\% at risk of malnourishment).

In high-income countries, the prevalence of malnutrition assessed with MNA is substantially higher among institutionalised elderly people $(30-70 \%)^{29,30}$ than among those living in their homes $(5-10 \%)^{21}$. Institutionalisation in these contexts indicates requiring intensified care due to sickness or frailty. In Bangladesh, there are no institutions for this special group of elderly people; hence all live at home with the exception of hospitalisation for acute cases. 


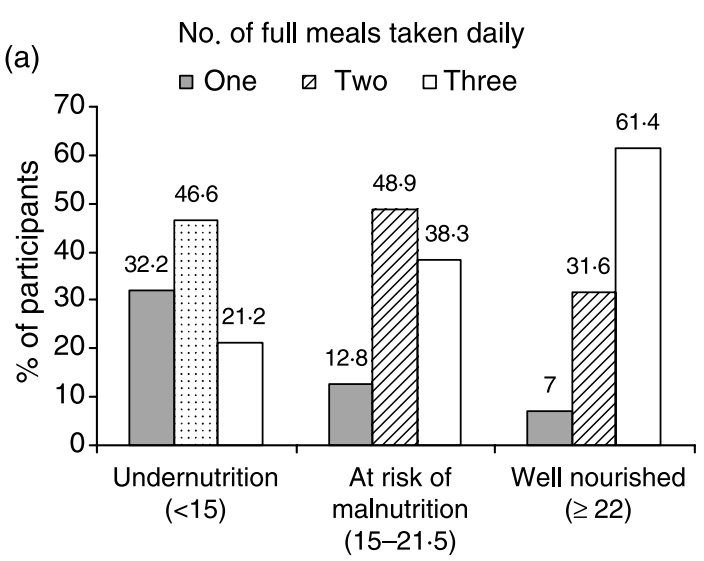

Nutritional status by MNA score

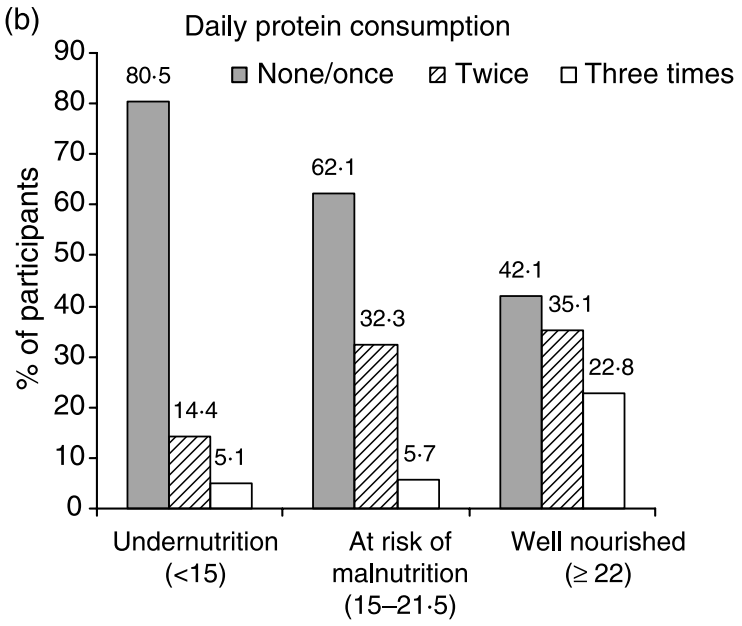

Nutritional status by MNA score
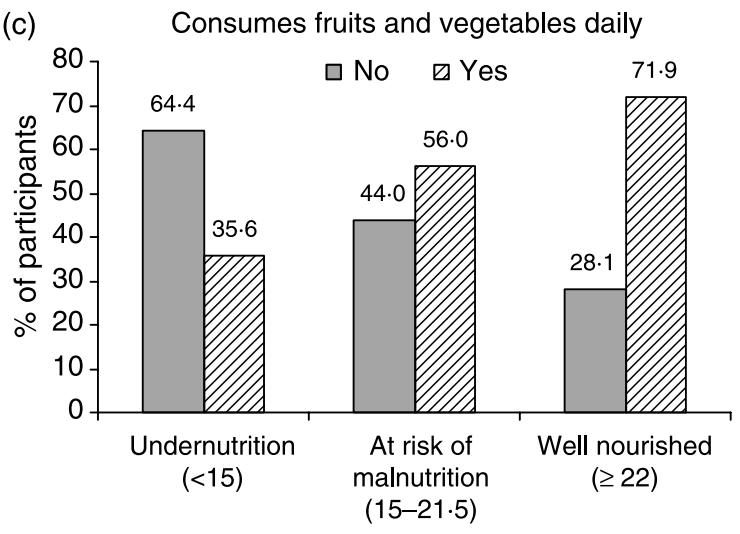

Nutritional status by MNA score

Fig. 2 Level of consumption of elderly persons in a rural area in Bangladesh according to nutritional status as evaluated by Mini Nutritional Assessment (MNA): (a) daily meal consumption; (b) daily protein consumption; (c) daily consumption of fruits and vegetables

Thus, the prevalence of PEM in free-living elderly persons in Bangladesh corresponds to that found among institutionalised and hospitalised chronically ill elderly individuals in affluent societies. Using MNA, Persson et al. $^{31}$ report similar prevalences of PEM (26\%) and moderate PEM or at risk of being PEM (56\%) among Swedish geriatric patients as found in our study. Thomas et $a l^{32}$ describe malnutrition to have reached epidemic proportions in a sub-acute care facility in St. Louis, USA, with the prevalence of either malnourished or at risk of malnutrition among its geriatric patients reported as more than $90 \%$, a figure similar to that in the present study. Among studies of non-institutionalised elderly persons in the USA and Europe, the prevalence of nutritional risk is reported to range between $18 \%$ and $41 \%$, whereas none were found to suffer from malnutrition ${ }^{33-35}$. Finally, in Asia, a population-based study in Taiwan using the MNA reports moderate and high risk of malnutrition among older persons ranging from $1.9 \%$ to $3.6 \%$, figures comparable to those of Europe ${ }^{36}$.

\section{Why are they undernourished?}

The alarmingly high prevalence of elderly people either undernourished or at risk of malnutrition in Bangladesh raises a number of issues. Research from Western societies indicates that, due to a complexity of factors, the prevalence of malnourishment is higher in the older population than younger adults. Health status rather than age itself is suggested as important in explaining malnutrition among older persons ${ }^{7,29}$. Based on this thinking, we modelled our regressions such that the predictors were ordered from general (demographic) to more specific (health).

Results from the present study also indicate that, among elderly persons, health problems rather than increment in chronological age has a greater negative impact on nutritional status. The results also indicate that level of education and expenditure on food are directly associated with nutritional status. Malnutrition in low-income countries is intrinsically related to food insecurity, resulting in sections of the population with low food intake $\mathrm{g}^{9,17}$. It is plausible in the current context that the high level of malnutrition found among the elderly is a cumulative effect of adverse economic factors occurring gradually through the life course and the presence of illness. Moreover, the simultaneous occurrence of abundant malnutrition and illness in the populations of lowincome countries imposes a dual burden on these societies, hampering their economic growth and development. In future studies, it is important to identify at what stage in this population malnourishment is likely to occur, and the determinants that sustain the status into old age. MNA is a tool to identify those at risk of malnutrition who can benefit from early intervention. Using MNA to describe nutritional status of the elderly in Bangladesh, our data suggest that more than half of elderly individuals are at risk of malnourishment in this rural community, persons who can potentially benefit from interventions. It can contribute in reducing susceptibility to health problems such as infectious diseases associated with low-income countries, and consequently increasing opportunities for 
Table 3 Hierarchical linear regression examining demographic, socio-economic and health indicators as predictors of nutritional status expressed by MNA scores

\begin{tabular}{|c|c|c|c|c|c|}
\hline Predictors & $\beta$ & $F$ & $P$-value & $R^{2}$ change & $\begin{array}{l}\text { Significance } \\
\text { of } R^{2} \text { change }\end{array}$ \\
\hline \multicolumn{6}{|l|}{ 1. Demographic indicators } \\
\hline Age in years & -0.122 & 6.6 & 0.01 & & \\
\hline Sex $($ Men $=1 ;$ Women $=2)$ & -0.133 & 7.9 & 0.005 & 0.032 & 0.001 \\
\hline \multicolumn{6}{|l|}{ 2. Socio-economic indicators } \\
\hline Years of schooling & 0.177 & 11.9 & 0.001 & & \\
\hline Per capita daily household expenditure in Taka* & 0.109 & 5.4 & 0.021 & 0.043 & 0.000 \\
\hline \multicolumn{6}{|l|}{ 3. Health indicators } \\
\hline Respiratory problem & -0.108 & 5.4 & 0.021 & & \\
\hline Stomach problem & -0.119 & 6.6 & 0.011 & & \\
\hline Pain & 0.035 & 0.5 & 0.491 & & \\
\hline Sensory problem & -0.171 & 12.8 & 0.000 & & \\
\hline Sleeping problem & -0.142 & 9.8 & 0.002 & 0.093 & 0.000 \\
\hline Total $R^{2}$ change & & & & 0.168 & \\
\hline
\end{tabular}

* Taka $57=\$$ US 1 during the study period.

healthy ageing. Note, however, that the current findings are correlational only and that no firm conclusions about causality may be drawn based on the findings presented here.

Finally, in order to achieve the first of the stated targets of Millennium Development Goals of halving world hunger in the coming decade, it is important to recognise that a substantial proportion of the elderly population, particularly in low-income countries, is undernourished.

\section{Acknowledgements}

The study was supported by grants from the Department for International Development, UK to the ICDDR,B: Centre for Population and Health Research, and from the Swedish Medical Research Council and the Swedish International Development Agency to ICDDR,B and the Karolinska Institute.

\section{References}

1 United Nations. What are the Millennium Development Goals? [online], 2005. Available at http://www.un.org/ millenniumgoals/. Accessed 5 January 2005.

2 United Nations. Millennium Summit Roadmap: goals and targets. UN Chronicle Online Edition 2001; XXXVIII(4). Also available at http://www.un.org/Pubs/chronicle/2001/ issue 4/0401cont.htm

3 Svedberg P. Poverty and Undernutrition: Theory, Measurement and Policy. Oxford: Oxford University Press, 2000.

4 Food and Agricultural Organization of the United Nations (FAO). The State of Food Insecurity in the World 2004. Rome: FAO, 2004.

5 Pirlich M, Lochs H. Nutrition in the elderly. Best Practice \& Research. Clinical Gastroenterology 2001; 15: 869-84.

6 Whitney EN, Rolfes SR, eds. Life cycle nutrition: adulthood and the later years. Understanding Nutrition, 9th ed. Belmont, CA: Wadsworth/Thomson Learning, 2002; 576-93.

7 Griep MI, Mets TF, Collys K, Ponjaert-Kristoffersen I, Massart DL. Risk of malnutrition in retirement homes elderly persons measured by the 'Mini-Nutritional Assessment'. Journal of
Gerontology. Series A, Biological Science and Medical Sciences 2000; 55A: M57-M63.

8 Rubenstein LZ, Harker JO, Salvá A, Guigoz Y, Vellas B. Screening for undernutrition in geriatric practice: developing the Short-Form Mini-Nutritional Assessment (MNA-SF). Journal of Gerontology. Series A, Biological Science and Medical Sciences 2001; 56A: M366-72.

9 Suzana S, Earland J, Suriah AR, Warnes AM. Social and health factors influencing poor nutritional status among rural elderly Malays. Journal of Nutrition, Health \& Aging 2002; 6: 363-9.

10 Omran ML, Morley JE. Assessment of protein energy malnutrition in older persons, Part I. History, examination, body composition, and screening tools. Nutrition 2000; 16 : $50-63$.

11 Akner G, Cederholm T. Treatment of protein-energy malnutrition in chronic nonmalignant disorders. American Journal of Clinical Nutrition 2001; 74: 6-24.

12 Flodin L, Svensson S, Cederholm T. Body mass index as a predictor of 1 year mortality in geriatric patients. Clinical Nutrition 2000; 19: 121-5.

13 Vellas BJ, Hunt WC, Romero LJ, Koehler KM, Baumgartner RN, Garry PJ. Changes in nutritional status and patterns of morbidity among free-living elderly persons: a 10-year longitudinal study. Nutrition 1997; 13: 515-9.

14 United Nations (UN). World Population Prospects: The 2002 Revision. Highlights. New York: UN, 2003.

15 World Health Organization. The World Health Report $2004-$ Changing History [online], 2004. Available at http://www. who.int/whr/2004. Accessed 4 January 2005.

16 Solomons NW. Health and ageing. In: Flores R, Gillepsie S, eds. Health and Nutrition: Emerging and Remerging Issues in Developing Countries. Washington, DC: International Food Policy Research Institute, 2001.

17 World Health Organization (WHO). Keep Fit for Life: Meeting the Nutritional Needs of Older Persons. Geneva: WHO and Tufts University School of Nutrition Science and Policy, 2002.

18 Islam MZ, Lamberg-Allardt C, Kärkkäinen M, Ali SMK. Dietary calcium intake in premenopausal Bangladeshi women: do socio-economic or physiological factors play a role? European Journal of Clinical Nutrition 2003; 57: 674-80.

19 Pryer JA, Rogers S, Rahman A. The epidemiology of good nutritional status among children from a population with a high prevalence of malnutrition. Public Health Nutrition 2003; 7: 311-7. 
20 Guigoz Y, Vellas B, Garry PJ. Assessing the nutritional status of the elderly: the Mini Nutritional Assessment as part of the geriatric evaluation. Nutrition Reviews 1996; 54: S59-65.

21 Vellas B, Lauque S, Andrieu S, Nourhashemi F, Rolland Y, Baumgartner R, et al. Nutrition assessment in the elderly. Current Opinion in Clinical Nutrition and Metabolic Care 2001; 4: 5-8

22 Kuzuya M, Kanda S, Koike T, Suzuki Y, Shosuke S, Iguchi A Evaluation of Mini-Nutritional Assessment for Japanese frail elderly. Nutrition 2005; 21: 498-503.

23 Visvanathan R, Zaiton A, Sherina MS, Muhammad YA. The nutritional status of 1081 elderly people residing in publicly funded shelter homes in Peninsular Malaysia. European Journal of Clinical Nutrition 2005; 59: 318-24.

24 Chilima DM, Ismail SJ. Anthropometric characteristics of older people in rural Malawi. European Journal of Clinical Nutrition 1998; 52: 643-9.

25 Kikafunda JK, Lukwago FB. Nutritional status and functional ability of the elderly aged 60 to 90 years in the Mpigi district of central Uganda. Nutrition 2005; 21: 59-66.

26 Hels O, Hassan N, Tetens I, Thilsted SH. Food consumption, energy and nutrient intake and nutritional status in rural Bangladesh: changes from 1981-1982 to 1995-96. European Journal of Clinical Nutrition 2003; 57: 586-94.

27 Ahmed F. Vitamin A deficiency in Bangladesh: a review and recommendations for improvement. Public Health Nutrition 1999; 2: 1-14.

28 Ahmed F. Anaemia in Bangladesh: a review of prevalence and aetiology. Public Health Nutrition 2000; 3: 385-93.
29 Cederholm T, Hellstrom K. Nutritional status in recently hospitalized and free-living elderly subjects. Gerontology 1992; 38: 105-10.

30 Saletti A, Lindgren EY, Johansson L, Cederholm T. Nutritional status according to Mini Nutritional Assessment in an institutionalized elderly population in Sweden. Gerontology 2000; 46: 139-45.

31 Persson MD, Brismar KE, Katzarski KS, Nordenström J, Cederholm TE. Nutritional status using Mini Nutritional Assessment and Subjective Global Assessment predict mortality in geriatric patients. Journal of the American Geriatric Society 2002; 50: 1996-2002.

32 Thomas DR, Zdrowski CK, Wilson M-M, Conright KC, Lewis $\mathrm{C}$, Tariq S, et al. Malnutrition in subacute care. American Journal of Clinical Nutrition 2002; 75: 308-13.

33 Beck AM, Ovesen L, Osler M. The 'Mini Nutritional Assessment' (MNA) and the Determine Your Nutritional Health Checklist (NSI) as predictors of morbidity and mortality in an elderly Danish population. British Journal of Nutrition 1999; 81: 31-6.

34 Guigoz Y, Vellas B, Garry PJ. Mini Nutritional Assessment: a practical tool for grading the nutritional state of elderly patients. Facts and Research in Gerontology 1994; (Suppl. 2): $15-81$.

35 Saletti A, Johansson L, Yifter-Lindgren E, Wissing U, Österberg K, Cederholm T. Nutritional status and a 3-year follow-up in elderly receiving support at home. Gerontology 2005; 51: 192-8.

36 Tsai AC, Chang JMC, Lin H, Chuang Y-L, Lin S-H, Lin Y-H. Assessment of the nutritional risk of $>53$-year-old men and women in Taiwan. Public Health Nutrition 2004; 7: 69-76. 